\title{
O poder de normalização e a produção do indivíduo perigoso
}

\author{
Gabriel Lacerda de Resende, ${ }^{I,}$ Rosane Azevedo Neves da Silva ${ }^{I I}$ \\ ${ }^{I}$ Universidade Federal Fluminense, Niterói, RJ, Brasil / Faculdades Integradas Maria Thereza, Niterói, RJ, Brasil \\ II Universidade Federal do Rio Grande do Sul, Porto Alegre, RS, Brasil
}

\begin{abstract}
Resumo
Partindo da análise de prontuários de internação de crianças e adolescentes no Hospital Psiquiátrico São Pedro, em Porto Alegre, observa-se, nos motivos de internação, componentes essencialmente morais, sem uma relação especifica com os diagnósticos. Tomando essa discrepância em análise, resgata-se, na obra de Michel Foucault, elementos que permitem a construção do conceito de "poder de normalização". Utilizando tal ferramenta conceitual, opera-se uma genealogia dos saberes e técnicas que fazem da internação psiquiátrica uma operação repleta de componentes morais, atentando para as forças que constituem esse campo no Hospital Psiquiátrico São Pedro.
\end{abstract}

Palavras-chave: história da psiquiatria; poder de normalização; indivíduo perigoso.

\section{The power of normalization and the production of the dangerous individual}

\begin{abstract}
Examining the hospitalization records of children and juveniles in the São Pedro Psychiatric Hospital, in Porto Alegre, one notices, in the hospitalization causes, essentialy moral aspects, with no specific relation to the diagnostics. Taking such discrepancy into analysis, we rescue, in the work of Michel Foucault, aspects which allow us to forge the notion of "power of normalization". Using such concept, we conduct a genealogic research of the knowledges and techniques that turn the psychiatric hospitalization into an operation full of moral components, paying attention to the forces that constitute such a field in the São Pedro Psychiatric Hospital.
\end{abstract}

Keywords: history of psychiatry; power of normalization; dangerous individual.

\section{Pistas para uma pesquisa}

A ideia que norteia esse trabalho está relacionada ao projeto de pesquisa "A problematização do normal e do patológico nos modos de ser criança e adolescente", cujo objetivo é investigar tanto as transformações daquilo que a sociedade considera como desviante da norma quanto as mudanças que ocorrem nas próprias ferramentas teórico-conceituais que permitem o diagnóstico - e, por que não, a invenção - de novas patologias, tomando como objeto de análise os prontuários de crianças e adolescentes internados no Hospital Psiquiátrico São Pedro. Esses documentos estão alocados no Arquivo Público do Estado do Rio Grande do Sul (dos mais antigos até, aproximadamente, a década de 1960) e nos arquivos do próprio Hospital Psiquiátrico São Pedro.

Neste artigo vamos priorizar a relação que se estabelece entre o poder de normalização e a produção do indivíduo perigoso (FOUCAULT, 1978/2006b), pois, ao analisarmos os prontuários de diferentes períodos históricos, encontramos notadamente os problemas de conduta como o principal motivo de internação de crianças e adolescentes no Hospital Psiquiátrico São Pedro.

\section{Poemas-vida ${ }^{1}$}

O ano situa-se em algum ponto entre as décadas de 1960 e 1970. O país fica do outro lado do Atlântico e acima da linha do Equador. Um pesquisador olha um documento datado de 1707. O documento tem algo a dizer sobre uma

\footnotetext{
^Endereço para correspondência: Universidade Federal Fluminense, Centro de Estudos Gerais, Instituto de Ciências Humanas e Filosofia. Rua Professor Marcos Waldemar de Freitas Reis - São Domingos. Niterói, RJ - Brasil. CEP: 24210201.E-mail: gablacres@gmail.com, rosane.neves@ufrgs.br

${ }^{1} \mathrm{Em} A$ vida dos homens infames, Foucault (2006a, p. 204) utiliza este termo para designar as narrativas presentes nos documentos que analisa: "Vidas singulares, tornadas, por não sei quais acasos, estranhos poemas, eis o que eu quis juntar em uma espécie de herbário".
}

vida: "Sua loucura consistiu sempre em ocultar-se da sua família, em levar uma vida obscura no campo, em passear sua pobre mente por rotas desconhecidas, e em acreditar-se capaz de ocupar os melhores empregos".

"Este não é um livro de história. [...] É uma antologia de existências" (FOUCAULT, 2006a, p. 203). É assim que Foucault começa o texto que serviria de introdução a um livro homônimo, nunca terminado: A vida dos homens infames. $\mathrm{O}$ autor conta que é a partir do encontro com documentos de admissão em distintas instituições do século XVIII que nasce a ideia central do texto: vidas indignas, existências fadadas ao esquecimento, que passariam ao largo dos grandes escritos sobre a história, não fosse seu encontro com o poder. Vidas como a que está relatada no parágrafo anterior. A elas só se pode aceder por essas linhas parcas; impossível resgatar pistas de como poderão ter sido em seu "estado livre". Essas palavras vazias são a parte que lhes cabe desse latifúndio:

As falas breves e estridentes que vão e vêm entre o poder e as existências as mais essenciais, sem dúvida, são para estas o único momento que jamais lhes foi concedido; é o que

lhes dá, para atravessar o tempo, o pouco de ruído, o breve clarão que as traz até nós (FOUCAULT, 2006a, p. 208).

De acordo com Foucault (2006a p. 211), esses escritos ilustram, muito particularmente, o entrecruzamento de mecanismos políticos e efeitos de discurso. O ponto onde se dá esse cruzamento é precisamente aquele em que cada vida torna-se objeto das tecnologias de poder. Dentro dessa perspectiva, tomar um dado de arquivo que discorre sobre uma vida não será tanto esperar que ele ilustre os infortúnios de determinada existência; ao admitirmos que o poder age e produz diversos efeitos sobre uma vida - e que o mesmo não deixa de acontecer na via 
contrária -, torna-se tarefa ética do pesquisador perguntar-se por que alguns pontos específicos da conduta de determinados sujeitos fazem questão ao poder, e como esse poder reage a essa espécie de questionamento obscuro, a um modo de vida que parece interrogá-lo justamente ali onde qualquer resposta parecerá incompatível com a pergunta. A existência que estava fadada à exclusão insiste e retorna no discurso que se produz sobre ela. Conforme Vasconcellos, C. e Vasconcellos, S. (2007), os insanos só são liberados das correntes por Pinel pelo fato de que elas não são mais necessárias, na medida em que as palavras, a partir de uma organizada nosologia, passam a permitir um outro tipo de aprisionamento. Caberá ao pesquisador abrir essas palavras e extrair delas os nós que tanto interrogam os saberes e poderes; questionamento que necessariamente dá a ver os dispositivos que produzem essas vidas. Cada palavra tecida sobre uma vida carrega consigo pistas da realidade, fragmentos discursivos e técnicas de poder. É nesse sentido que Foucault (2006a, p. 206) coloca que estamos diante de

textos que desempenharam um papel nesse real do qual falam, e que se encontram, em contrapartida, não importa qual seja sua exatidão, sua ênfase ou sua hipocrisia, atravessados por ela: fragmentos de discurso carregando os fragmentos de uma realidade da qual fazem parte.

De certo modo, poderíamos dizer que esses fragmentos de discurso são o próprio disparate sobre o qual a genealogia vai se debruçar; isto é, contêm, em si, enquanto acontecimento, a dimensão da história efetiva ${ }^{2}$ de que nos fala Foucault. O pensador francês coloca que "as forças que se encontram em jogo na história não obedecem nem a uma destinação, nem a uma mecânica, mas ao acaso da luta [...] Elas aparecem sempre na álea singular do acontecimento" (FOUCAULT, 1998, p. 28).

$\mathrm{Na}$ esteira dessas ideias, importa-nos tomar cada dado histórico não como mais um elo de uma corrente que seria unidirecional, obediente a uma sequência teleológica dotada de um valor primeiro e último, mas sim contemplá-lo em sua singularidade, encontrar pistas daquilo que produz o próprio dado, que forças entram em combate para que algo passe às páginas da história.

Eis nossa abordagem em relação aos prontuários do Hospital Psiquiátrico São Pedro; no encontro com as palavras que dizem de uma vida, a postura do pesquisador não será tanto a da aceitação daquilo que já foi dito como dado preciso de realidade, mas, antes, a de puxar esses fragmentos de realidade para fora do enunciado; a de debruçar-se sobre o que possibilita que se diga o que se diz sobre uma vida em determinado recorte histórico, bem como os efeitos de poder dessas práticas discursivas:

Vidas reais foram 'desempenhadas' nestas poucas frases; não quero dizer com isso que elas ali foram figuradas, mas que, de fato, sua liberdade, sua infelicidade, com freqüência sua morte, em todo caso seu destino foram, ali, ao menos em parte, decididos (FOUCAULT, 2006a, p. 207).

\footnotetext{
Em "Nietzsche, a genealogia e a história", Foucault (1998, p. 28) coloca que "a história 'efetiva' faz ressurgir o acontecimento no que ele pode ter de único e agudo".
}

\section{Entre farelos e palavras: o encontro com os prontuários}

Pastas de papel dobradas, tal qual fossem livros, contêm os distintos documentos que compõem cada prontuário; não há homogeneidade no arranjo daquilo que os constitui: uns contêm tão somente uma ficha de admissão e de alta; outros abrigam pareceres dos médicos responsáveis, telegramas da Chefatura de Polícia da cidade de origem, um ou outro exame solicitado pelos médicos. Há fotos dos internos; elas parecem ser o produto impreciso de um estranho embate entre um lado que quer saber avidamente como é o rosto daquilo que está do outro lado da lente, e outro que sempre escapa, não se deixa capturar. O resultado são retratos que oscilam entre o onírico e o assustador, como se servissem de propaganda aos antigos circos de horrores. Alguns destes documentos perdem pequenos pedaços conforme são manuseados, não tanto na forma de um rasgo que seria causado por um descuido, mas na de um inevitável esfarelamento; como se algo ali só dependesse do contato humano para virar pó: "o tempo destrói tudo". 3

Mas algo havia de resistir ao tempo, e tomado por essa crença avançamos pelos prontuários, em busca daqueles que diziam respeito às internações de crianças e adolescentes. As palavras saltam aos olhos, fazem-se visíveis, audíveis: estranhos acordes de uma composição dissonante. Um jovem que chegara ao hospício por ser "masturbador profissional" recebe o diagnóstico de demência precoce e debilidade mental. Outro é internado por "amoralidade". Mais adiante, explica-se: queria casar-se escondido porque o pai não aprovava o relacionamento. Recebe o diagnóstico de "psicopatia constitucional" e "estado atípico de degeneração". Há ainda uma menina, internada por ter sido estuprada por um desconhecido. Oligofrênica, dizem os peritos. Distúrbios de conduta, modificações de caráter, atos imorais, pobres que necessitam de tratamento, distúrbios do procedimento, má conduta: motivos de internação que dizem de uma inadequação do sujeito àquilo que dele é esperado. Diagnósticos desencontrados para os mesmos motivos de internação, como se o jogo do confinamento psiquiátrico fosse um grande quebra-cabeça composto por peças incompatíveis: esquizofrenia, sífilis, oligofrenia, psicose induzida, loucura moral, debilidade mental, mania aguda, demência precoce, degeneração atípica, psicopatia constitucional... Curioso desacordo de um saber que se diz tão preciso e certeiro.

Algo resistia ao tempo: os poemas-vida extrapolavam as parcas linhas que a eles haviam sido dedicadas. Algo resistia ao tempo na forma de perguntas: o que conecta um diagnóstico a um motivo de internação? Que dados são importantes para que um diagnóstico seja formulado? A que responde uma internação psiquiátrica? $\mathrm{O}$ que faz com que uma conduta seja categorizada através de uma nosografia psiquiátrica? Por que a psiquiatria leva quase cem anos para chegar a um certo "acordo" em relação aos diagnósticos possíveis para aqueles que eram internados por questões relacionadas à conduta? Inconclusas questões ${ }^{3}$ Frase que guia o filme Irreversivel (2002) de Gaspar Noé. 
oriundas do contato com o dito "dado", que nos apontavam a necessidade de furar os enunciados dos prontuários, olhar para além deles, por detrás, para as próprias condições de enunciação colocadas ali. Pesquisar não tanto para interpretar e entender o dado, mas para desestabilizá-lo, cortar a suposta verdade que ele carrega; tarefa ética do pesquisador que olha o passado para interrogar o presente.

\section{Para cortar (ou um conceito)}

Coloquemos, então, as peças nos devidos lugares: os pacientes eram internados por motivos relacionados a uma certa moral, por questões concernentes a uma conduta que desviava da norma esperada; por outro lado, o diagnóstico dado a eles parecia não guardar nenhuma relação mais específica com esses motivos, como se não desse conta, como se não fosse suficiente para corroborar a suspeita inicial. E mais, havia uma variedade de diagnósticos, muitas vezes antagônicos, que respondiam a um motivo de internação que era essencialmente invariável; como se os próprios saberes que atuam na produção desses diagnósticos não conseguissem encontrar um terreno comum, uma resposta homogênea - "científica", para usarmos um termo caro aos arautos do conhecimento que desse conta daquele motivo de internação. É somente por volta da década de 1980 que essa discrepância entre motivo de internação e diagnóstico parece ser resolvida, como se finalmente houvesse um consenso em torno dos destinos possíveis daqueles que eram internados por alguma questão relacionada à conduta. Nessa época, vemos surgir três diagnósticos específicos que agrupam os pacientes que haviam sido internados por tais motivos: transtorno de conduta, transtorno de personalidade antissocial e transtorno de ajustamento.

A partir desses disparos, vislumbrávamos pistas para uma questão: a que responde a internação de uma criança ou de um adolescente num hospital psiquiátrico? Que instituições, saberes e discursos operam aí? Responderão somente aos avanços inequívocos de uma ciência infalível, à benevolência de tratar as enfermidades alheias, ou veicularão uma certa moral, em defesa da sociedade? O que embasa e legitima os diagnósticos conferidos àquelas pessoas? Por que é somente na década de 1980 que os saberes em jogo parecem finalmente encontrar um diagnóstico que dê conta dos motivos de internação relacionados à conduta do indivíduo?

Eis o dado, mas precisávamos abri-lo, furá-lo, ver o que o sustentava. Para realizar tal tarefa, tínhamos algumas perguntas que nos guiariam durante o percurso; perguntas que não necessariamente exigiriam uma resposta simétrica, mas que, antes, iluminassem o trajeto, indicassem uma escolha possível dos caminhos.

Deleuze diz, e a nós faz sentido dizer com ele: "Cada conceito corta o acontecimento, o recorta a sua maneira" (DELEUZE; GUATTARI, 1992, p. 47). Necessitávamos de um operador conceitual. Uma ferramenta para dar a ver o terceiro lado da moeda, inaugurando uma superfície em que fosse possível cortar mais do que entender. E foi no fortuito encontro com o pensamento de Foucault que vislumbramos uma possibilidade de início.
Em seu curso de 1975 no Collège de France, intitulado Os Anormais, Foucault (2010) apresenta, en passant, um conceito que ele chama - temporariamente, como faz questão de frisar - de "poder de normalização". De acordo com ele, esse poder seria a expressão de uma "miscibilidade institucional", ${ }^{4}$ com um polo psiquiátrico e um polo judiciário, porém com regras independentes tanto da psiquiatria quanto do judiciário. Esse poder responderia ao perigo. O conceito pareceu-nos de grande valia para guiar nosso pensamento através de uma hipótese: o que estaria em jogo nessas internações seria, portanto, um certo movimento de cerceamento ao perigo, que seria representado pelas crianças e adolescentes "desviantes".

Para dar conta deste percurso seria necessário, portanto, traçar linhas que nos permitissem vislumbrar os disparates que vão moldando esse "poder de normalização" nos diferentes momentos, os pequenos acidentes que fazem surgir um novo diagnóstico aqui, uma categoria diferente ali; não tomar essas eclosões como fruto de um desenvolvimento teleológico e inequívoco da história, mas vislumbrar as rupturas, as permanências, as transformações que, em dado período, permitem que surja um enunciado sobre a loucura, sobre o perigo, e não outro. Olhar atento para as condições de possibilidade de emergência dos saberes que vão delimitar o indivíduo perigoso, que vão definir a quem compete sua guarda, quem produz conhecimento sobre ele e o que se faz com esse conhecimento.

Neste sentido, esse escrito traça uma trajetória que não é unidirecional: procura entender os percursos das patologias da infância e da adolescência no Hospital Psiquiátrico São Pedro, debruçando-se sobre os principais disparates que vão permitindo novos e descartando velhos enunciados sobre a loucura e sobre o perigo; intuir como e a partir de que condições se dá essa miscibilidade entre psiquiatria e judiciário, entendendo o produto que daí advém como "poder de normalização"; vislumbrar como, num contexto biopolítico, o diagnóstico psiquiátrico acaba funcionando como um traço de inteligibilidade que conecta ato e autor, permitindo que se conheça "quem ele realmente é" e atualizando sua periculosidade virtual em um motivo de internação.

\section{Método}

Em "Nietzsche, a genealogia e a história", Foucault vai retornar à obra do filósofo alemão para evidenciar um modo de enxergar a história: a genealogia. Segundo Foucault (1998), Nietzsche vai criticar a ideia de origem, porque tal noção implicaria em tentar encontrar a essência da coisa, "sua forma imóvel e anterior a tudo o que é externo, acidental, sucessivo"; como se a origem fosse o lugar da verdade, bastião da pureza e verdade do acontecimento. Ainda com Foucault (1998, p. 28):

Há toda uma tradição da história (teleológica ou racionalista) que tende a dissolver o acontecimento singular em uma continuidade ideal - movimento teleológico ou enca-

${ }^{4}$ Reproduzimos aqui a Nota do Tradutor: "Mixité institutionelle. Mixité (que traduzimos por 'miscibilidade') é a qualidade do que é misto, em particular do que reúne elementos, pessoas, de origem (cultural, étnica, etc.) diversa". Uma imagem pertinente para o conceito é a da mistura da gasolina com a água: dois líquidos distintos que formam um terceiro; diferente, mas detentor de características de ambos.

Fractal, Rev. Psicol., v. 28 - n. 3, p. 324-332, 2016 
deamento natural. A história 'efetiva' faz ressurgir o acontecimento no que ele pode ter de único e agudo.

Sendo assim, a partir de uma perspectiva genealógica, "o sentido histórico [...] reintroduz no devir tudo o que se tinha acreditado imortal no homem" (FOUCAULT, 1998, p. 27. Isso significa olhar para a história como um campo de forças heterogêneas, únicas, fugazes, que vão constituindo condições de possibilidade para determinados acontecimentos. Seria um olhar para o disparate, para aquilo que torna possível a emergência de um determinado conceito, de um determinado saber e, consequentemente, a que ele busca responder.

Através dessa lupa com a qual enxergaremos a história, importa atentar para aquilo que continua nos inquirindo, não obstante o "passar do tempo". Em nossa pesquisa, esse olhar implica em aceitar uma concepção pouco paradoxal do tempo, onde a produção dos mais variados discursos sobre o normal e o patológico na infância e na adolescência não pode ser tomada como uma evolução unidirecional do conhecimento científico, porque carregam a permanência dos mecanismos de exclusão e patologização de modos de vida que não se conformam às normas da sociedade. A relação que o pesquisador estabelecerá com a história, portanto, não será pela via da confirmação do atual através da linearidade dos fatos passados; antes disso, trata-se de atentar para como a história nos interroga acerca do presente. Tomá-la como motor da pergunta e não como mecanismo de resposta:

Trata-se de retirar da história aquilo que deve permanecer nos interrogando, constituindo uma dimensão de simultaneidade [...] e não apenas de sucessividade [...]. Somente assim poderemos buscar estratégias de diferenciação, resistência e constituição de linhas de fuga (ZAMBENEDETTI; SILVA, 2011, p. 459).

\section{O diagnóstico como traço de ligação entre ato e autor}

\begin{tabular}{|l|l|l|}
\hline \multicolumn{2}{|c|}{ Tabela 1 } \\
\hline $1884-1937$ & $\begin{array}{l}\text { MOTIVO DE INTERNAÇÃO } \\
\text { DIAGNÓSTICO }\end{array}$ \\
\hline & $\begin{array}{l}\text { Atos imorais, delinquência, } \\
\text { masturbador profissional, } \\
\text { amoralidade, vício de } \\
\text { mendicância, desvio de } \\
\text { conduta }\end{array}$ & $\begin{array}{l}\text { Mania aguda e subaguda, } \\
\text { epilepsia, demência precoce, } \\
\text { debilidade mental, degeneração } \\
\text { atípica, psicopatia } \\
\text { constitucional, loucura moral }\end{array}$ \\
\hline $1938-1955$ & $\begin{array}{l}\text { Distúrbios de conduta, menor } \\
\text { degenerado, pobres que } \\
\text { necessitam de tratamento, } \\
\text { paciente órfão, masturbação } \\
\text { desatada }\end{array}$ & $\begin{array}{l}\text { Oligofrenia, esquizofrenia, } \\
\text { psicose infecciosa, estados } \\
\text { mentais não classificados, } \\
\text { imbecilidade }\end{array}$ \\
\hline $1956-1979$ & $\begin{array}{l}\text { Distúrbio de conduta, má } \\
\text { conduta, conduta agressiva, } \\
\text { conduta desajustada, } \\
\text { problema de conduta, } \\
\text { cleptomania, quer seduzir } \\
\text { mulheres casadas }\end{array}$ & $\begin{array}{l}\text { Estados ansiosos, psicose } \\
\text { psicogênica, reação } \\
\text { esquizofrênica tipo paranoide, } \\
\text { transtorno de personalidade não } \\
\text { especificado, personalidade } \\
\text { psicopática, síndrome } \\
\text { esquizofreniforme, autismo } \\
\text { infantil, psicose simbiótica }\end{array}$ \\
\hline $1980-2001$ & $\begin{array}{l}\text { Reprovado na escola, sério } \\
\text { problema de conduta, más } \\
\text { companhias, agressividade } \\
\text { verbal e física, delinquente, } \\
\text { brigas na escola }\end{array}$ & $\begin{array}{l}\text { Transtorno de conduta, } \\
\text { transtorno de personalidade } \\
\text { antissocial, transtorno de } \\
\text { ajustamento }\end{array}$ \\
\hline
\end{tabular}

A partir dessa tabela, é possível observar que há uma grande variedade de diagnósticos ao longo dos anos, associados a um motivo de internação que permanece essencialmente o mesmo: "problema de conduta, distúrbio de conduta, má conduta, conduta desajustada..." Essa discrepância parece produzir uma tensão no próprio saber psiquiátrico, como se este não soubesse como dar conta, do ponto de vista do diagnóstico, de uma internação motivada por algo na conduta do sujeito que desviasse do esperado. Essa desarmonia parece ser "resolvida" em meados da década de 1980 - ano de lançamento do DSM III -, que inaugura uma série de novas categorias nosográficas, incluindo os diagnósticos específicos de "transtorno de conduta, transtorno de personalidade antisocial e transtorno de ajustamento". Nesse sentido, esses diagnósticos, em sua especificidade, funcionam como uma ferramenta que integra o ato à conduta global do sujeito, como uma lente de aumento que mostra quem ele “realmente é". Foucault (2006b) já havia dito que para que a máquina punitiva funcione, não basta que exista uma infração real que se possa imputar a um culpado: é preciso estabelecer uma relação psicologicamente inteligível entre ato e autor. Com a aproximação da psiquiatria na gestão do campo da periculosidade social, pode-se dizer que "o duro ofício de punir vê-se assim alterado para o belo ofício de curar" (FOUCAULT, 2010, p. 21).

\section{Fazer amarras}

Para construir o operador conceitual que norteia a hipótese desse trabalho - "o poder de normalização" -, faz-se necessário percorrer um espectro mais amplo da obra de Foucault, que vai além da cunhagem deste conceito, por diversas razões. Primeiramente, é imprescindível caracterizar o regime de poder que torna possível a emergência do referido conceito, a saber, a "biopolítica"; em seguida, é preciso caracterizar as noções de "normação" e "normalização" que o pensador francês constrói, especialmente em seu seminário Segurança, território e população (FOUCAULT, 2009), ministrado em 1978. Vale lembrar que o uso do termo "normalização", no que concerne à obra de Foucault, geralmente está referido ao argumento que o autor desenvolve no seminário supracitado - no sentido de uma "operação de normalização", mais ampla, que abarcaria o exercício do que aqui chamamos "poder de normalização" - e que, portanto, esta ideia que pretendemos desenvolver aqui pode acarretar uma confusão conceitual entre os termos. Neste sentido, retomaremos um texto pouco explorado de Foucault (1978/2006b), A evolução da noção de 'indivíduo perigoso' na Psiquiatria Legal do século $X I X$, a partir da hipótese de que as ideias trabalhadas nesse texto dizem respeito, fundamentalmente, àquilo que ele havia nomeado alguns anos antes (e lembremos que ele ressalta o caráter provisório dessa nomeação) como "poder de normalização". Dessa forma, tal conceito versa, da maneira como é apresentado neste escrito, sobre a tessitura de um plano operada por nós mesmos, cada ponto buscando amarrar diversas ideias que Foucault ha- 
via enunciado: "pequenos catalisadores do pensamento, multiplicadores de bifurcações nos caminhos predeterminados das nossas ideias" (SANDER, 2010, p. 382). Tomamos a liberdade de compor com as distintas peças de um pensamento, na medida em que a colagem nos pareceu útil para pensar a problemática que se apresentava. Caixa de ferramentas, portanto.

\section{Biopolítica, ou o corpo social como realidade biológica}

Ainda que o conceito de biopolítica tenha sido enunciado pela primeira vez em 1974, em uma conferência proferida no Instituto de Medicina Social da Universidade do Estado do Rio de Janeiro (UERJ) - e publicada em 1977 sob o título de $O$ nascimento da medicina social (FOUCAULT, 1984) -, pode-se dizer que é no último capítulo de História da Sexualidade: a vontade de saber que Foucault (1982) aborda a questão de modo mais incisivo e sistematizado (CAPONI, 2012).

$\mathrm{O}$ autor parte da ideia de poder soberano para desenvolver o conceito de biopolítica. Segundo ele, o soberano poderia dispor da vida de seus súditos. Assim, quando estivesse em perigo, era-lhe lícito pedir que tomassem parte na defesa do Estado; expor suas vidas sem pretender direta e necessariamente sua morte. Mas se um deles se insurge contra ele, o soberano pode exercer um poder direto - matá-lo:

O soberano só exerce, no caso, seu direito sobre a vida, exercendo seu direito de matar ou contendo-o; só marca seu poder sobre a vida pela morte que tem condições de exigir. O direito que é formulado como 'de vida e de morte' é, de fato, o direito de causar a morte ou de deixar viver (FOUCAULT, 1982, p. 128, grifo do autor).

Foucault coloca que, desde a Idade Clássica, o Ocidente operou um profundo deslocamento neste mecanismo de poder.

Mas esse formidável poder de morte [...] apresenta-se agora como o complemento de um poder que se exerce, positivamente, sobre a vida, que empreende sua gestão, sua majoração, sua multiplicação, o exercício, sobre ela, de controles precisos e regulações de conjunto. As guerras já não se travam em nome do soberano a ser defendido; travam-se em nome da existência de todos; populações inteiras são levadas à destruição mútua em nome da necessidade de viver. Os massacres se tornaram vitais (FOUCAULT, 1982, p. 129).

Trata-se agora, portanto, de fazer viver e rejeitar para a morte - um poder positivo sobre a vida. Tal racionalidade desenvolveu-se, de acordo com o autor, sob duas formas principais: um processo de disciplinarização do corpo (anátomo-política do corpo humano) e uma série de intervenções e controles reguladores sobre o corpo populacional (biopolítica da população). A biopolítica, então, vai preocupar-se com a vida da "população", com a sobrevivência da espécie, e não com o corpo individualizado de cada um (objeto do poder na racionalidade disciplinar). Sendo população um conceito demográfico, quantificável, a racionalidade biopolítica acaba por transformá-la num organismo normalizável, através de processos de normalização das condutas. Tem como objetivo retirar a presença e a força política desse corpo populacional e reduzir as vidas a meras existências biológicas - vida nua, para dizer com Agamben (2010). Noções como o corpo, a saúde, a natalidade, pertencentes em idos tempos a uma esfera que seria pré-política, ingressam no campo da política (CAPONI, 2012, p. 24); passam a ser as peças que deslizam sobre o tabuleiro da gestão da vida da população. Eis o que se coloca em xeque: "[...] o conjunto dos mecanismos pelos quais aquilo que, na espécie humana, constitui suas características biológicas fundamentais vai poder entrar numa política, numa estratégia política, numa estratégia geral de poder" (FOUCAULT, 2009, p. 3).

Se o fato da vida é posto em primeiro plano, concordaremos que há aí um deslocamento fundamental na maneira como o corpo social é tratado: passagem de uma metáfora jurídico-política para uma realidade biológica (FOUCAULT, 1978/2006b, p. 9). Urbanização, grandes populações e mão de obra industrial em larga escala são apenas alguns dos fatores que vão colocar o problema das condições de existência, de habitat, de alimentação das populações humanas, através de fenômenos como as epidemias, endemias e a mortalidade infantil. Nesse deslocamento, a faceta biológica das populações se constitui enquanto um terreno de intervenção médica; terreno no qual a psiquiatria terá um papel muito específico, que explicitaremos mais adiante.

\section{Norma e normalidades diferenciais}

É em Segurança, território e população que Foucault (2009) vai caracterizar - como o leitor certamente poderá intuir - o que caracteriza um dispositivo de segurança, colocando-o em uma série que compreenderia a seguinte sequência: dispositivo jurídico-legal - dispositivo disciplinar - dispositivo de segurança. ${ }^{5}$ Em determinado momento de sua análise, o pensador francês vai distinguir o modo como o dispositivo disciplinar e o dispositivo de segurança tratam da questão da normalização.

Para Foucault, a produção de uma individualidade disciplinar corresponde a quatro técnicas, quais sejam: distribuição dos corpos no espaço; controle da atividade; organização da gênese; composição das forças. Estas técnicas decompõem os indivíduos, os gestos, os lugares, os tempos, buscando estabelecer os elementos mínimos de percepção e suficientes de modificação (FOUCAULT, 2009). "Quais são os melhores gestos a fazer para obter determinado resultado? Qual é o melhor gesto a fazer para carregar o fuzil [...], os operários mais aptos para determinada tarefa?" (FOUCAULT, 2009, p. 75). É através dessa análise minuciosa, dessa decomposição em mínimas unidades que se estabelecerá o funcionamento ideal de determinado procedimento. Nesse sentido,

A normalização disciplinar consiste em primeiro colocar um modelo, um modelo ótimo que é construído em função

\footnotetext{
${ }^{5}$ Foucault ressalta que não se trata de uma sequência cronológica: “[...] vocês não têm uma série na qual os elementos vão se suceder, os que aparecem fazendo seus predecessores desaparecerem" (FOUCAULT, 2009, p. 11). Trata-se de evidenciar as relações "[...] que fazem com que, numa sociedade dada e para este ou aquele setor dado [...] se instale uma tecnologia de segurança, por exemplo, que leva em conta e faz funcionar no interior da sua tática própria elementos jurídicos, elementos disciplinares [...]" (FOUCAULT, 2009, p. 12).
} 
de certo resultado, e a operação de normalização disciplinar consiste em procurar tornar as pessoas, os gestos, os atos, conformes a esse modelo, sendo normal precisamente quem é capaz de se conformar a essa norma e o anormal quem não é capaz. Em outros termos, o que é fundamental e primeiro na normalização disciplinar não é o normal e o anormal, é a norma $[\ldots]$ se trata muito mais de uma normação do que de uma normalização. Perdoem-me o barbarismo, mas é para melhor salientar o caráter primeiro e fundamental da norma (FOUCAULT, 2009, p. 75).

Portanto, no dispositivo da disciplina, estabelece-se primeiro a norma, através dessa mínima decomposição dos elementos de cada ato; e a partir dela, divide-se o conjunto dos corpos entre normal e anormal. A norma é primeira: ou o sujeito é louco, ou ele não é. Foucault cita como exemplo cabal desse dispositivo os regulamentos traçados diante da peste na Idade Média: trata-se de esquadrinhar as cidades, estabelecendo um regimento que indique às pessoas quando podem sair, quando fazê-lo, o que devem comer, proibindo-lhes certos tipos de contato e obrigando-lhes a abrir a casa diante dos inspetores (FOUCAULT, 2009, p. 14).

Já para caracterizar o dispositivo de segurança, Foucault vai partir do exemplo da varíola e de sua respectiva vacinação, elencando quatro noções que emergem junto com esse dispositivo. $\mathrm{O}$ autor coloca que a partir da vacinação foi possível introduzir nos indivíduos uma "pequena doença", mas de maneira tal que essa inoculação artificial, ao invés de resultar na doença total e completa, permitisse prevenir os outros eventuais ataques da varíola (FOUCAULT, 2009, p. 78). Caso, risco, perigo e crise: noções novas que requerem

[...] toda uma série de formas de intervenção que vão ter por meta, não se fazer como se fazia antigamente, ou seja, tentar anular pura e simplesmente a doença em todos os sujeitos em que ela se apresenta, ou ainda impedir que os sujeitos que estejam doentes tenham contato com os que não estão (FOUCAULT, 2009, p. 81).

Se na disciplina o que está em jogo é tratar a doença no indivíduo e de isolar os doentes dos não-doentes, a segurança vai levar em conta o conjunto sem descontinuidade - ou seja, a população - e ver qual é o coeficiente de morbidade provável, o que é normalmente esperado em matéria de doença, de morte. A técnica, portanto, vai consistir “em procurar reduzir as normalidades mais desfavoráveis, mais desviantes em relação à curva normal, geral, reduzi-las a essa curva normal, geral" (FOUCAULT, 2009, p. 82). É nesse sentido que o autor aponta que

Aqui, ao contrário, vamos ter uma identificação do normal e do anormal, vamos ter uma identificação das diferentes curvas de normalidade, e a operação de normalização vai consistir em fazer essas diferentes distribuições de normalidade funcionarem umas em relação às outras e em fazer de sorte que as mais desfavoráveis sejam trazidas às que são mais favoráveis. Temos, portanto, aqui uma coisa que parte do normal e que se serve de certas distribuições consideradas, digamos assim, mais normais que as outras, mais favoráveis em todo caso que as outras. São essas distribuições que vão servir de norma. A norma está em jogo no interior das normalidades diferenciais. O normal é que é primeiro, e a norma se deduz dele, ou é a partir desse estudo das normalidades que a norma se fixa e desempenha seu papel operatório. Logo, eu diria que não se trata mais de uma normação, mas sim, no sentido estrito, de uma normalização (FOUCAULT, 2009, p.83).

Já não importa tanto quem é normal e quem é anormal - quem está doente e quem está saudável. O que é premente é saber a normalidade da cada caso anormal: quem adoece mais fácil, um bebê ou um adulto? Dentro do conjunto dos bebês, o que está mais exposto à varíola é aquele que habita o campo ou a cidade? É dentro desse jogo das normalidades diferenciais, dessa distribuição interior e pulverizada da norma, que a psiquiatria vai se inserir como uma defensora generalizada da sociedade. Não se tratava somente de aplicar uma nova racionalidade médico-científica às desordens psíquicas, mas de funcionar como uma forma de higiene pública. Poderíamos apontar que esse deslocamento fundamental se dá através da teoria da degeneração enunciada por Morel. Para ele, "os seres degenerados formam grupos e famílias com elementos distintivos relacionados invariavelmente às causas que os transformaram nisso que são: um desvio mórbido do tipo normal da humanidade" (MOREL apud CAPONI, 2012, p. 22). Portanto, essas condutas anormais, desviantes, aberrantes vão ser o eixo articulador dessa nova psiquiatria, na medida em que se estabelece um vínculo entre elas e um estado anormal, herdado e definitivo. Trata-se de uma herança não definida e imprevisível, em que toda e qualquer anomalia pode surgir e espalhar-se a partir de um sujeito tido como degenerado. Nessa visão, os anormais não portam uma doença em particular, mas antecipam um número ilimitado e indefinido de doenças possíveis em sua descendência (CAPONI, 2012, p. 26). Estabelece-se, portanto, uma "medicina do não patológico", campo magno de atuação da psiquiatria dentro do espectro de uma gestão do social. Face obscura do jogo biopolítico, essa "medicina do não patológico" engendra uma série de políticas higiênicas, psiquiátricas e eugênicas que, buscando melhorar a população e a raça, multiplicam as condutas anormais que podem ser alvo de intervenção médica (CAPONI, 2012, p. 25).

Aquilo em relação ao que elas [as condutas anormais] aparecem, é um nível de desenvolvimento ótimo: 'imaturidade psicológica', 'personalidade pouco estruturada', 'profundo desequilíbrio'. É igualmente um critério de realidade: 'má apreciação do real'. São qualificações morais [...] (FOUCAULT, 2010, p. 15, grifo nosso).

Nesse sentido,

O conhecimento médico naturaliza a moral. A dupla série de causas - físicas e morais - responsáveis pelo comportamento humano se inter-relaciona no interior do indivíduo. Como técnica de intervenção, a medicina, corrigindo os excessos que os homens cometem, visa justamente a estabelecer um estado de equilíbrio entre os aspectos físicos e morais (MACHADO et al, 1978, p. 281, apud WADI, 2002, p. 97). 
Se para Pinel o que importa é uma classificação binária - ou o sujeito é louco, ou não o é -, e se ele defende que a terapêutica da loucura só pode ser desenvolvida no interior do asilo psiquiátrico, a teoria inaugurada por Morel vai colocar que a "herança patológica deixa marcas no corpo que se transmitem por gerações, sendo a causa principal das patologias mentais" (CAPONI, 2012, p. 39). $\mathrm{O}$ alcance do saber psiquiátrico extrapola os muros do hospício, pois é necessário buscar na família, no entorno do indivíduo, os signos comprobatórios de sua loucura; extrapola, também, a esfera de uma origem orgânico-psíquica para as enfermidades mentais, já que no juízo dos psiquiatras da época a loucura estava relacionada a más condições de existência - como superpopulação, promiscuidade, alcoolismo, entre outras -, ou era percebida como fonte de perigos - para si, para os outros, para os demais e também para a descendência por mediação da herança (FOUCAULT, 1978/2006b, p. 9). Nesse sentido, a psiquiatria estabelece-se como "uma medicina concebida como reação aos perigos inerentes ao corpo social" (FOUCAULT, 1978/2006b, p. 9). Gestão do perigo no âmbito social e ampliação do corpo da doença, ${ }^{6}$ portanto.

\section{O poder de normalização e a construção da noção de indivíduo perigoso ${ }^{7}$}

Na lição inaugural do seu curso Os Anormais, a 8 de janeiro de 1975, Foucault (2010) aponta uma certa miscibilidade entre os poderes judiciário e psiquiátrico, através do exemplo dos exames psiquiátricos em matéria penal. A partir dos "grandes crimes de loucura" explicação racional aparente, o poder psiquiátrico começa a surgir na cena do tribunal, convocado a elucidar as motivações do indivíduo para um crime sem razão manifesta. É, portanto, a partir dos "crimes monstruosos" que se começa a esboçar um território comum entre os saberes da psiquiatria e da justiça; nesse sentido, o que a psiquiatria do século XIX faz é inventar a identidade fictícia de um crime que é todo loucura, uma loucura cujo ponto de expressão máximo e irrefutável é precisamente o "crime monstruoso"; um crime contra a natureza humana, em outras palavras. Em um primeiro momento, portanto, a interface dos poderes psiquiátrico e judiciário se dá a partir de uma certa urgência legal; é necessário saber se o sujeito é louco ou não, se seu crime é a expressão última de sua loucura, para saber se a ele é possível atribuir responsabilidade pelo crime que cometeu. Uma questão que parece se colocar a partir de uma exigência processual e burocrática, colocada para cada indivíduo, e não tanto a inscrita em uma determinada maneira de gerir

\footnotetext{
${ }^{6}$ Sandra Caponi (2012), comentando Foucault, coloca que o autor falava de um "alongamento do corpo" sobre o qual a psiquiatria se debruçaria, referindo-se à família afetada por uma série de conflitos e patologia, responsável pela hereditariedade da degeneração.

${ }^{7}$ Nesta seção, traremos desenvolvimentos referentes a duas obras de Foucault, intercalando-os; como já explicitado anteriormente, a construção da ideia central desse trabalho se dá justamente na aposta de uma amarragem possível entre esses escritos. Ou seja, Foucault, em nenhum momento, escreveu que o que ele havia chamado "poder de normalização" em Os Anormais era o objeto de seu ensaio $A$ evolução da noção de 'indivíduo perigoso' na Psiquiatria Legal do século XIX; nossa hipótese é a de que, por mais que a nomenclatura tenha sido abandonada no ensaio, ele trata, efetivamente, daquilo que ele havia nomeado alguns anos antes como "poder de normalização".

${ }^{8} \mathrm{O}$ exemplo cabal é o caso de Henriette Cornier, abordado por Foucault (2010) em Os Anormais, entre outros textos.
}

o corpus social. O autor coloca que, nessa miscelânea, o exame psiquiátrico é a ferramenta que vai buscar responder aos apelos da justiça aos psiquiatras, exercendo a função de repetir tautologicamente a infração, estabelecendo-a como traço constitutivo do indivíduo. Nesse sentido, ele permitiria "passar do ato à conduta, do delito à maneira de ser, e de fazer a maneira de ser se mostrar como não sendo outra coisa que o próprio delito, mas, de certo modo, no estado de generalidade na conduta de um indivíduo" (FOUCAULT, 2010, p. 15).

Mas se é a partir dos grandes crimes que a psiquiatria se aproxima da justiça, através da inserção muito pontual do exame psiquiátrico na dinâmica do tribunal, o esboço de um poder comum a ambos os campos, muito mais tentacular e difuso, começa a se delinear a partir das exigências de um regime de poder biopolítico. Foucault (1978/2006b) aponta, em A evolução da noção de 'indivíduo perigoso' na Psiquiatria Legal do século XIX alguns deslocamentos importantes realizados pela escola italiana de antropologia criminal. Para os teóricos dessa escola, a diferenciação a ser feita não era entre responsáveis que deveriam ser condenados e irresponsáveis que não devem sê-lo, mas "[...] entre sujeitos absoluta e definitivamente perigosos e aqueles que, por meio de certos tratamentos, deixam de sê-lo" (FOUCAULT, 1978/2006b, p. 18).

E é justamente no momento em que a psiquiatria parece se afastar do direito, quando a questão da responsabilização penal é colocada em segundo plano, que se funda um campo híbrido que vai dar conta de maneira mais eficiente da gestão higiênica do campo social. Não se trata de um psiquiatra que diga ao juiz se o sujeito está em plena posse de suas faculdades mentais ou não, para que esse juiz então determine se ele é responsável ou não pelo seu crime. O que vemos surgir aí é um poder que vai dar conta do perigo virtualmente existente no indivíduo antes mesmo que seja necessário saber se ele é culpado ou não; o que temos é uma zona comum, cuja constituição se deve em parte ao funcionamento da medicina como higiene pública e em parte ao funcionamento da punição legal como técnica de transformação individual. Um funcionamento "parapatológico e infralegal" ou a constituição de um "duplo psicológico-moral" (FOUCAULT, 2010) que, colado ao sujeito, vai mostrar como toda sua história de vida, seu entorno familiar, suas pequenas condutas mundanas, são prejudiciais ao bom andamento da sociedade. Através dessa colagem, amplia-se o espectro de atuação de um saber psiquiátrico; não na direção de algo que seria a "cura" desse sujeito perigoso, mas, antes, na colocação em primeiro plano, da gestão do corpo social, de um saber que vai dizer "quem o sujeito realmente é". Um saber que vai permitir antecipar o perigo inerente a certas populações, integrando essa virtualidade em categorias psiquiátricas, ligando-a a uma determinação psicológica incontornável. A esse poder composto por vetores judiciários e psiquiátricos, mas com suas regras próprias, a esse continuum com um polo expiatório e um polo terapêutico, que responde essencialmente ao perigo, Foucault chamou "poder de normalização".

Fractal, Rev. Psicol., v. 28 - n. 3, p. 324-332, 2016 


\section{Alienado criminoso ou criminoso alienado?}

Cabe relatar aqui um exemplo retirado de um prontuário, que acreditamos ilustrar bem o exercício do "poder de normalização" no Hospital Psiquiátrico São Pedro. Nas correspondências entre a Casa de Correção, a Chefatura de Polícia e o Hospício, encontram-se os pontos de incidência do poder sobre a vida de um residente da Casa de Correção, que, em audiência, recusa-se a tirar o chapéu e a sentar-se diante do Juiz. Ele diz: "Não quiz tirar o chapeo porque me achava bem com o chapeo na cabeça e mesmo porque alli não era Egreja! Não quiz sentar-me porque entendi que devia estar de pé, mesmo alli não era casa de familia"!

Preso por ser "gatuno incorrigível", como consta na folha de identificação do Gabinete de Identificação e Estatística, ele acaba por circular entre um polo judiciário e um polo psiquiátrico, ora como "criminoso alienado", ora como "alienado criminoso": "Em todo o caso se não é um alienado é um candidato a alienação e como tal, acha-se em condições de ser internado no Hospicio $S$. Pedro a fim de ser devidamente observado" (Carta do médico da Casa de Correção ao Chefe de Polícia).

[...] sinão é um "anti-social" é um "extra-social”, isto é, um individuo que deve viver fóra da sociedade [...] deve ficar recluso ou numa secção de criminosos alienados na Casa de Correção, ou numa secção de alienados criminosos, no "Hospicio S. Pedro" [...] é um internado insubordinavel, pois affirmamos ser o epileptico mais perigoso, sob ponto de vista da ordem social, que nos tem cahido sob a observação de medicos legistas (Carta do médico legista da Chefatura de Polícia ao Diretor do Hospício São Pedro, grifo nosso).

O que vemos aí é uma variação sutil no enunciado; dependendo do especialista que fala, a característica que prevalece no sujeito é a do criminoso ou do alienado. No entanto, não resta dúvida a respeito do caráter de periculosidade do indivíduo, esteja ela situada na possibilidade de um desvio de conduta ou de uma patologia mental. Nesse sentido, acreditamos que se trata de um exemplo cabal do que, ao longo do trabalho, tentamos conceituar como "poder de normalização".

\section{Considerações finais}

Ao longo deste escrito, procuramos operar, através da análise de prontuários do Hospital Psiquiátrico São Pedro, um olhar que compreende um certo campo de problematizações, detectando as variações e as permanências dos discursos sobre a patologia na infância e na adolescência. Para este fim, trabalhamos com o operador conceitual "poder de normalização"; nesta construção, produzimos amarras entre diferentes linhas do pensamento de Foucault, visando à tessitura coerente do referido operador conceitual.

É a partir de um disparate no percurso da psiquiatria - a teoria da degeneração - que o eixo de intervenção deste saber é deslocado "das doenças às condutas, das patologias às anomalias, dos sintomas indicativos de lesões orgânicas às síndromes de degeneração" (CAPONI, 2012, p. 26). Ampliação do campo de atuação da psiquiatria, que agora tem cadeira cativa na gestão dos perigos sociais: "o que caracteriza essa nova psiquiatria é o poder dos médicos sobre o não patológico" (FOUCAULT apud CAPONI, 2012, p. 26).

Buscamos, ainda, apontar certa insuficiência e desacordo do saber psiquiátrico no que tange ao diagnóstico de internações motivadas por questões relacionadas à conduta, discrepância que parece se resolver com a emergência de categorias nosográficas que passam a agrupar essas internações. Nesse sentido, o diagnóstico cumpriria o papel de integrar um ato desviante à conduta global do sujeito, tal como as insígnias infantis confirmam a patologia do indivíduo adulto. Tentamos, dessa forma, contribuir no entendimento de uma ampliação do alcance do poder psiquiátrico, onde não é mais suficiente dizer se o sujeito é ou não é louco, mas antes constituir-se como uma ciência das condutas normais e anormais (FOUCAULT, 2010, p. 269). Através dessa análise, apostamos na possibilidade de produzir furos em um saber que se diz tão magnânimo e irrefutável. Um olhar genealógico para as pequenas erupções da história da psiquiatria possibilita a percepção de sua própria descontinuidade e insuficiência, e refuta sua pretensa objetividade precisa, ontem e hoje. Evitar os passos da psiquiatria, que buscou as explicações de origem da loucura, e debruçar-se sobre as condições de emergência da própria loucura enquanto objeto de saberes e técnicas específicos, eis o fio condutor da cruzada que tentamos empreender. Afinal, Lima Barreto já escrevera na segunda década do século XX:

Todas essas explicações da origem da loucura me parecem absolutamente pueris. Todo problema de origem é sempre insolúvel; mas não queria já que determinassem a origem, ou explicação; [...] Até hoje, tudo tem sido em vão, tudo tem sido experimentado; e os doutores mundanos ainda gritam nas salas diante das moças embasbacadas, mostrando os colos e os brilhantes, que a ciência tudo pode (LIMA BARRETO, 2010, p. 68).

\section{Referências}

AGAMBEN, G. Homo Sacer: o poder soberano e a vida nua. Belo Horizonte: UFMG, 2010. v. 1.

CAPONI, S. Loucos e degenerados: uma genealogia da psiquiatria ampliada. Rio de Janeiro: Fiocruz, 2012.

DELEUZE, G.; GUATTARI, F. O que é a filosofia? Rio de Janeiro: Editora 34, 1992.

FOUCAULT, M. História da sexualidade: a vontade de saber. Rio de Janeiro: Graal, 1982. v. 1.

FOUCAULT, M. O nascimento da medicina social. In: MACHADO, R. (Org.). Microfisica do poder. 4. ed. Rio de Janeiro: Graal, 1984. p. 79-98.

FOUCAULT, M. Nietzsche, a genealogia e a história. In: MACHADO, R. (Org.). Microfisica do poder. Rio de Janeiro: Graal, 1998. p. 15-37.

FOUCAULT, M. A vida dos homens infames. In: MOTTA, M. B. da (Org.). Estratégia, Poder-Saber. Rio de Janeiro: Forense Universitária, 2006a. Coleção Ditos \& Escritos, v. 4, p. 203222.

FOUCAULT, M. A evolução da noção de 'indivíduo perigoso' na Psiquiatria Legal do século XIX (1978). In: MOTTA, M. B. 
da (Org.). Ética, Sexualidade, Política. Rio de Janeiro: Forense Universitária, 2006b. Coleção Ditos \& Escritos, v. 5, p. 1-25.

FOUCAULT, M. Segurança, território e população. São Paulo: Martins Fontes, 2009.

FOUCAULT, M. Os Anormais. São Paulo: WMF Martins Fontes, 2010.

IRREVERSÍVEL. Diretor: Gaspar Noé. França: 120 Films et al., 2002. 1 DVD.

LIMA BARRETO, A. H. Diário do hospício; O cemitério dos vivos. São Paulo: Cosac Naify, 2010.

SANDER, J. A caixa de ferramentas de Michel Foucault, a reforma psiquiátrica e os desafios contemporâneos. Psicologia \& Sociedade, v. 22, n. 2, p. 382-387, maio/ago. 2010. Disponível em: <http://www.scielo.br/pdf/psoc/v22n2/19.pdf >. Acesso em: 22 jul. 2013.

VASCONCELLOS, C. T. D. V.; VASCONCELLOS, S. J. L. A doença mental feminina em Porto Alegre, Rio Grande do Sul, Brasil, (1870-1910). Cad. Saúde Pública, v. 23, n. 5, p. 10411049, mai. 2007. Cross ${ }^{\text {Ref. }}$

WADI, Y. M. Palácio para guardar doidos: uma história das lutas pela construção do hospital de alienados e da psiquiatria no Rio Grande do Sul. Porto Alegre: UFRGS, 2002.

ZAMBENEDETTI, G.; SILVA, R. N. Cartografia e genealogia: aproximações possíveis para a pesquisa em psicologia social. Psicologia \& Sociedade, v. 23, n. 3, p. 454-463, set./dez. 2011. Disponível em: <http://www.scielo.br/scielo.php?script=sci arttext\&pid=S0102-71822011000300002>. Acesso em: 22 jul. 2013.

Recebido em: 12 de agosto de 2013 Aceito em: 16 de julho de 2015 